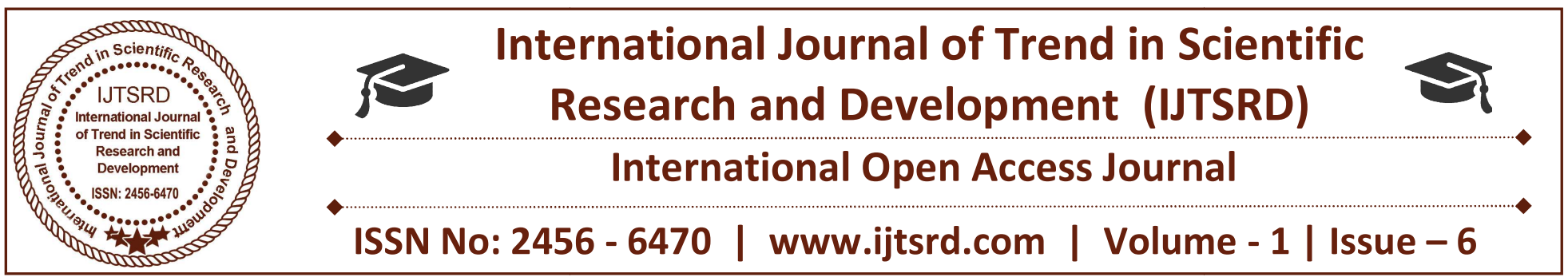

\title{
Improvement (Kaizen) Very High Fixture Set up Time on VMC Machine
}

\author{
Makarand Prabhakar Lehekar \\ Deogiri Institute of Engineering \& \\ Technology, Aurangabad, India
}

\author{
Prof. Mangesh Urne \\ Deogiri Institute of Engineering \& \\ Technology, Aurangabad, India
}

\author{
Prof. Mrs. Suvarna Pingle \\ Associate Professor, PES college \\ of engineering, Nagsenvan, \\ Aurangabad, India
}

\section{INTRODUCTION}

Nowadays the automotive industry is facing various problems because of changing global scenario in terms of high quality expectation, reduced cost of production and increased productivity. All the companies are in the motive to solve these problems through the application of modern techniques. This project attempts to provide an effective solution for these problems through lean manufacturing techniques. The key objective of this project is to eliminate the wastes and cost of production and to increase the quality and productivity through shorter lead time and increased value added activities. This project deals with collection of the time taken for each processes and the bottleneck operations have been identified and a current state of value stream map was developed. The suggestions were made by identifying and implementing various improvements in processes, also to develop the future state value stream map for further improvements to achieve the objectives of this project.

\section{Objective \& Necessity of the Project}

In today's scenario suppliers have a great concern over improving quality and delivery and decreasing cost, which leads to improved system productivity? In order to remain competitive, waste from the value stream must be identified and eliminated so to run system with maximum efficiencies.

A Production is to order and large numbers of different products are produced, each in relatively small volume.

\section{The problems of Pre-assembly productions are}

$>$ delayed deliveries,

$>$ long queues, and

$>$ high work in process inventories,

$>$ Improper utilization.

$>$ Various Muda's like

○ Defects

- Over production

- Waiting

- Not utilizing human potential

$>$ Transport

$>$ Inventory

$>$ Motion

$>$ Extra processing

These problems increase overall cost of production. The need for customized products/parts with reduced lead times together with the requirement of global competitiveness requires that products/parts be produced in small batch sizes as per customer's requirement.

The processing in small batch sizes necessitates:

$>$ The adjustment in the flow of production through different processes as per their processing speeds.

$>$ In addition it requires close monitoring of processes to reduce process variability (defect free production),

$>$ efficient planned maintenance of all machines (for increased availability) and

Reduction in non-value added activities such as (i) setup times, (ii) movement of material in between the work processes and (iii) additional processing 
of material.

The efficient utilization of machines while producing in small batches reduced WIP inventories, reduced times and reduction in lead times leads to competitive manufacturing. It is need for machine shop manufacturing system to adopt lean environment. To improve productivity by identifying waste and then removing that by implementing lean principle in this industry

\section{THEME OF THE PROJECT}

The theme of the project is to "To improve productivity of the pre-assembly production like machine shop by identifying various wastes and then removing all those wastes by application of Kaizen \& lean principles"

\section{Preface of this problem:}

The devices which are produced in instrumentation companies are highly customized $\&$ tailor made so there are high no of set up changes on all the machines in machine shop. There are on an average 5 to 6 set ups in a day (1 shift) which lead to huge time expediture on set up time which is a Non value adding activity \& thus MUDA.

Due to introduction of new Guided Wave Radar, various options introduced in existing products line \& increased local value addition, the machining content of the total production process has drastically increased.

Also due to various different parts machining, number of fixtures has increased on VMC machine

This has increased enormous pressure on machine shop. It lead to increased set up time on VMC machine as each fixture change is a major set up.

Since we wanted to improve this process we have decided to study the process in depth. So we caluculated total time spent in VA's \& NVA's i.e. Machining time \& set up time. Also the scrap cost encured due to more no. of set ups \& also the various delays due to this huge amount of set up time expediture. This data helped us to analyse the situation before \& after kaizen implementation.

\section{Data Collection before Kaizen:}

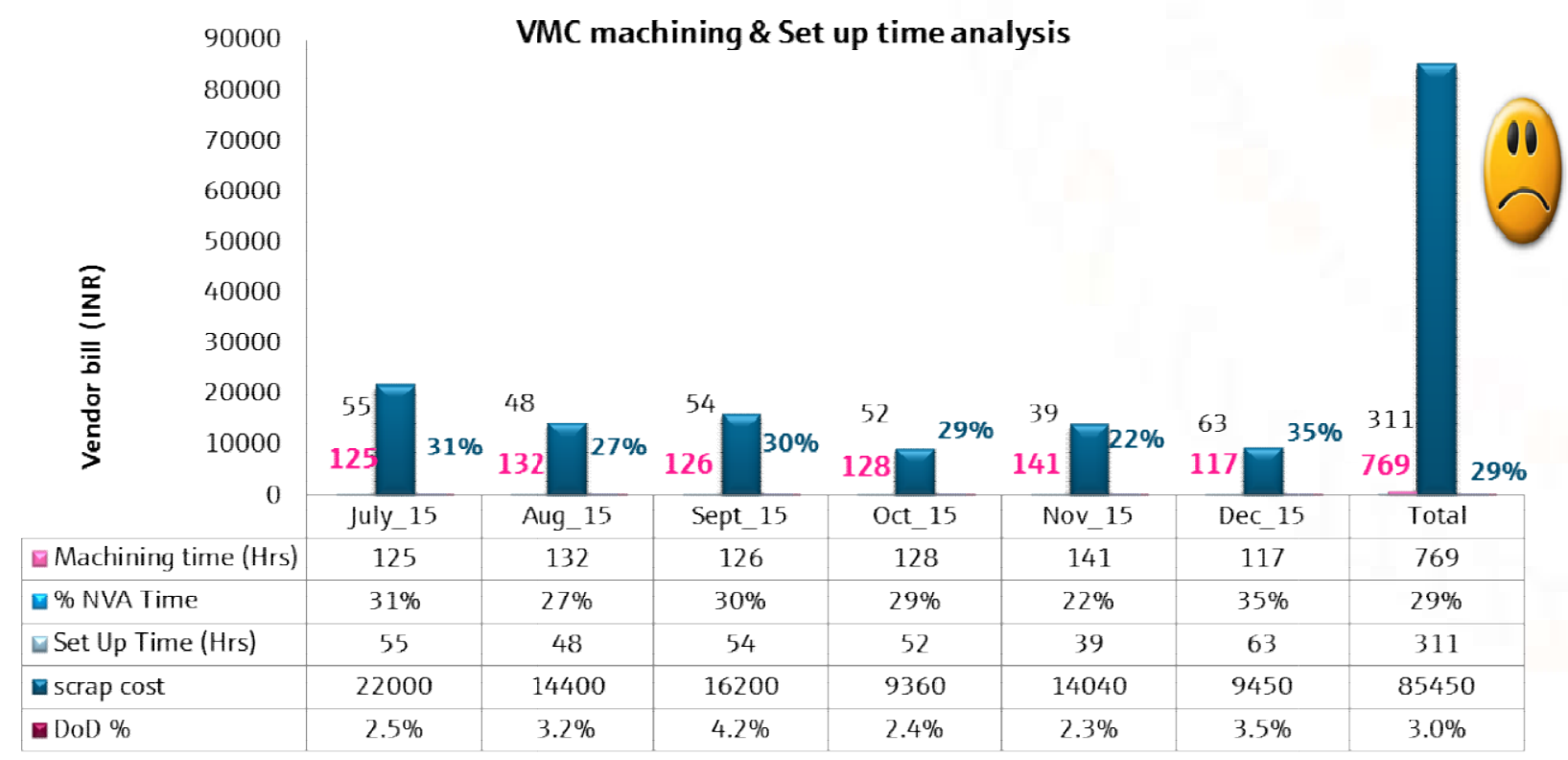

After this data collection it is very clear that actual machining time was $769 \mathrm{hrs}$ whereas total time spent for set up was $311 \mathrm{hrs} /$ month. This means 29\% of total time was spent on set up only which is NVA.
Also total Scrap cost incurred till 12/2015 was Rs. 85450. The scrap was generated mostly while doing set ups. So more no of set ups means more no of scraps generation. 
Many time due to more time required for set up \& machining the flow from machining to assembly line was disrupted \& so missing deliveries to customer. This has resulted in Customer dissatisfaction on delays contributing 3\% delays due to material not received from VMC.

\section{Pareto Analysis of various set times}

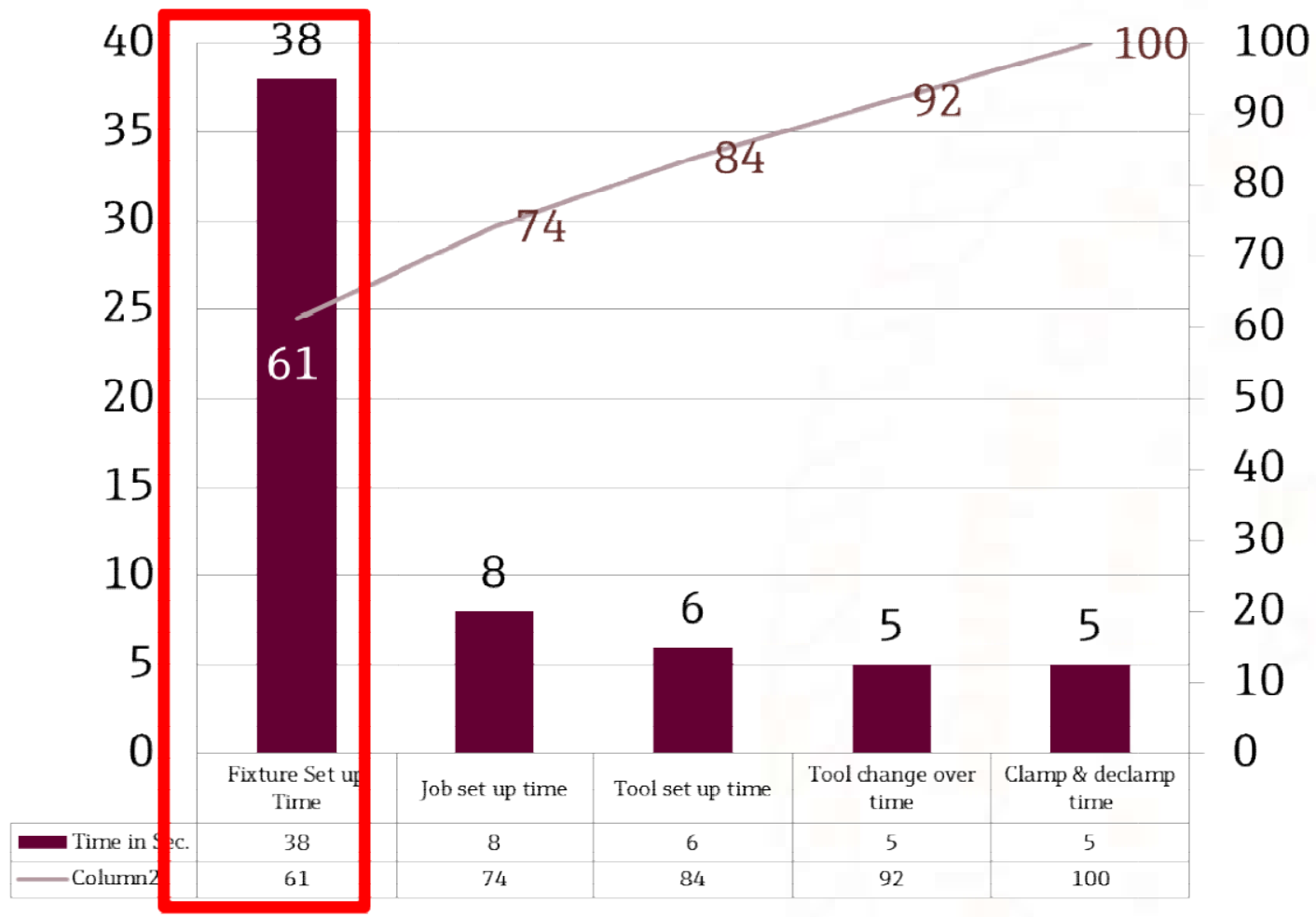

With Pareto analysis of various NVA's time on VMC, it is very clear that Fixture setting was contributing highest time. So Kaizen Theme is Fixture Set up time reduction.

We plotted above problem in Ishikawa diagram to find out various causes \& their effects. This is to find out if those are related to man, machine, material, process, management $\&$ environment. 


\section{Identification of causes \& effects by Fish bone diagram:}

\section{Fish Bone for Problem - Fixture set up time reduction}

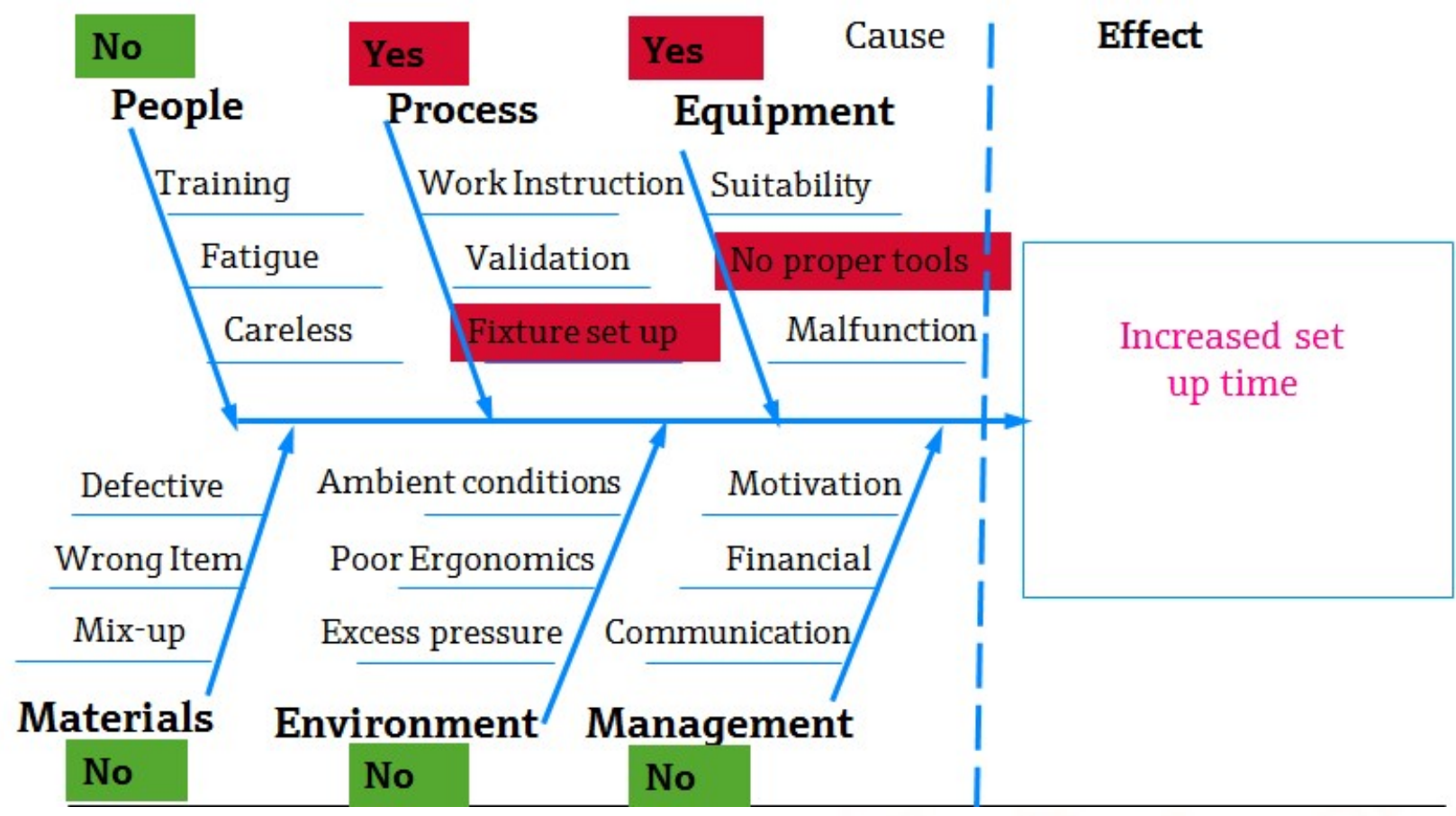

Finding out the root cause by Why analysis:

\section{For Process \& Equipment}

\section{Problem: Fixture set up time more}

Why?

When new fixture is loaded on machine, the position of all the sides of the fixture needs to be taught to machine.

Why?

Every time fixture won't be placed on the exactly same place.

Why?

No provision for placing it on exactly the same position.

YES, we will make such provision

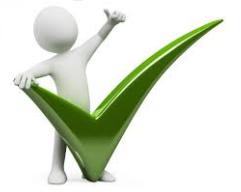

\section{Brainstorming For Solution:}

- Root cause: No provision for placing fixture on exactly the same position every time.

Can we make Automatic robotic arrangement for fixture trueing?

Possible but it is very expensive \& also still it will take time \& set up wouldn't be reduced so much.

Can we provide some reference dowel pins so that fixture can be placed exactly the same position?

Yes, we can solve this problem by making dowel holes \& pins on SMED fixture so that all the fixtures can be placed on the same position every time

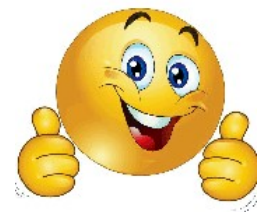




\section{Design of the Fixture Plate:}
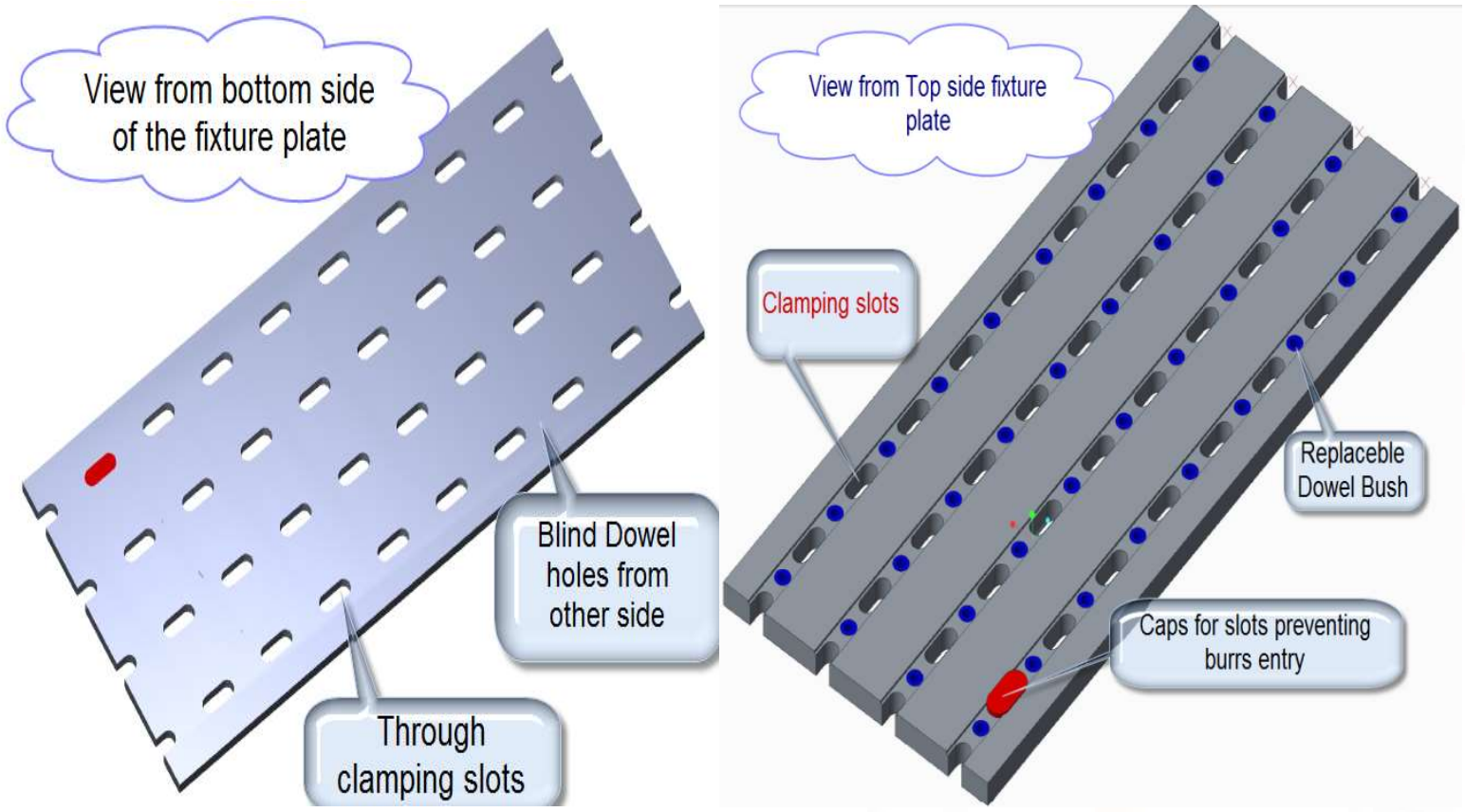

\section{Developing Solution:}

$\checkmark$ We have prepared the design of the fixture plate.

$\checkmark$ The clamping slots \& dowel holes with bushes are made

$\checkmark$ Similar dowel holes are made on all the fixtures we have.

$\checkmark$ The position of the fixture is fixed

$\checkmark$ For each fixture, only once set up has to be done.

$\checkmark$ After $1^{\text {st }}$ set up, only fix the fixture on the defined dowel holes with the Dowel pins.

$\checkmark$ Then Cycle start. No need to true the fixture at all.

$\checkmark$ This is a single minute change of fixture

$>$ After Kaizen Analysis of various set times:

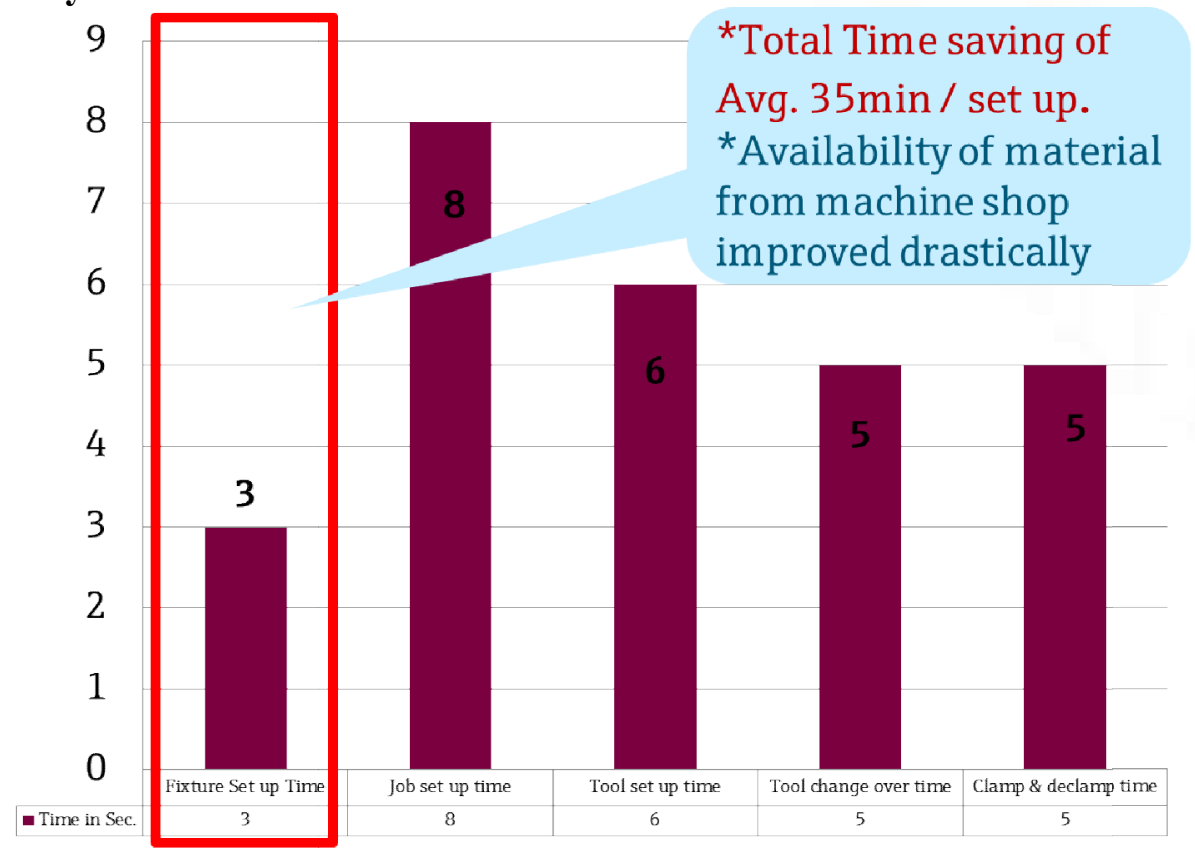


After Kaizen implementation analysis it is clearly seen that there is drastic reduction in fixture set up time i.e. from 35 mins to 3 mins. This means single minute change of fixture.

\section{Data analysis (During trial implementation):}

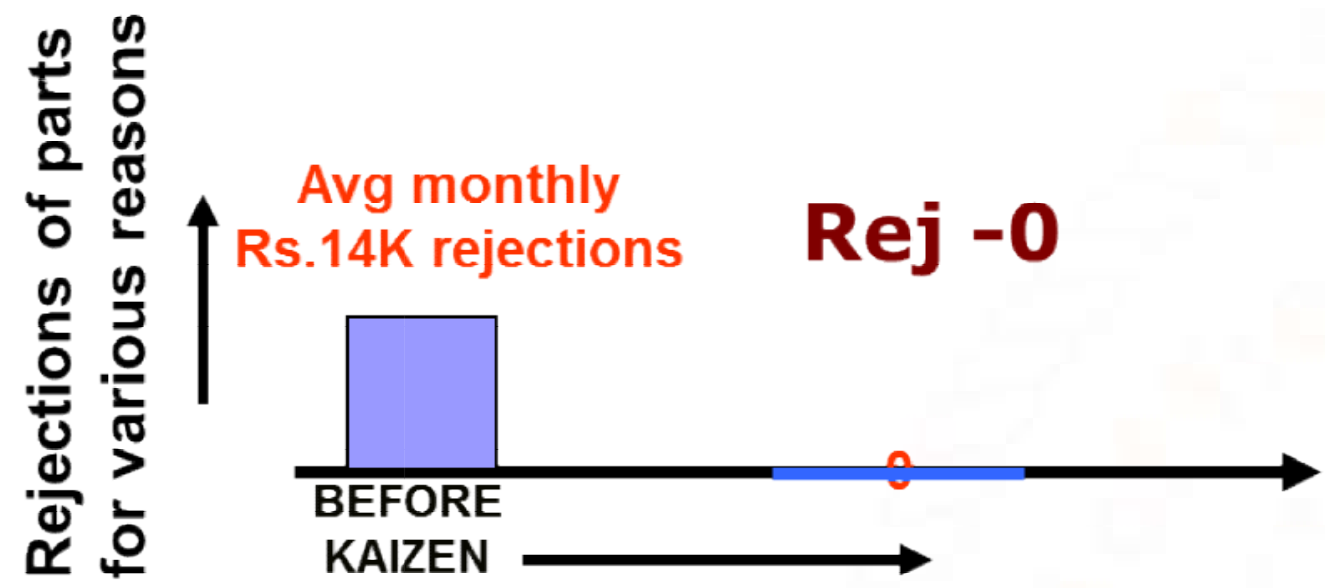

After implementation of SMED fixture plate, production is running smoothly with excellent quality \& with almost no set up time for fixtures. Our delivery performance has improved to avg. 98\% until last month in current year.

\section{Follow Up \& Review}

1) For regular inspection format prepared which is to be used after each new set up.

2) Monthly inspection of dowel pins \& dowel bush carried out to ensure dowel pin \& bushes are worn out or not.

3) Standard operating procedures have been modified, incorporating the solution

\section{SOP for Operation}

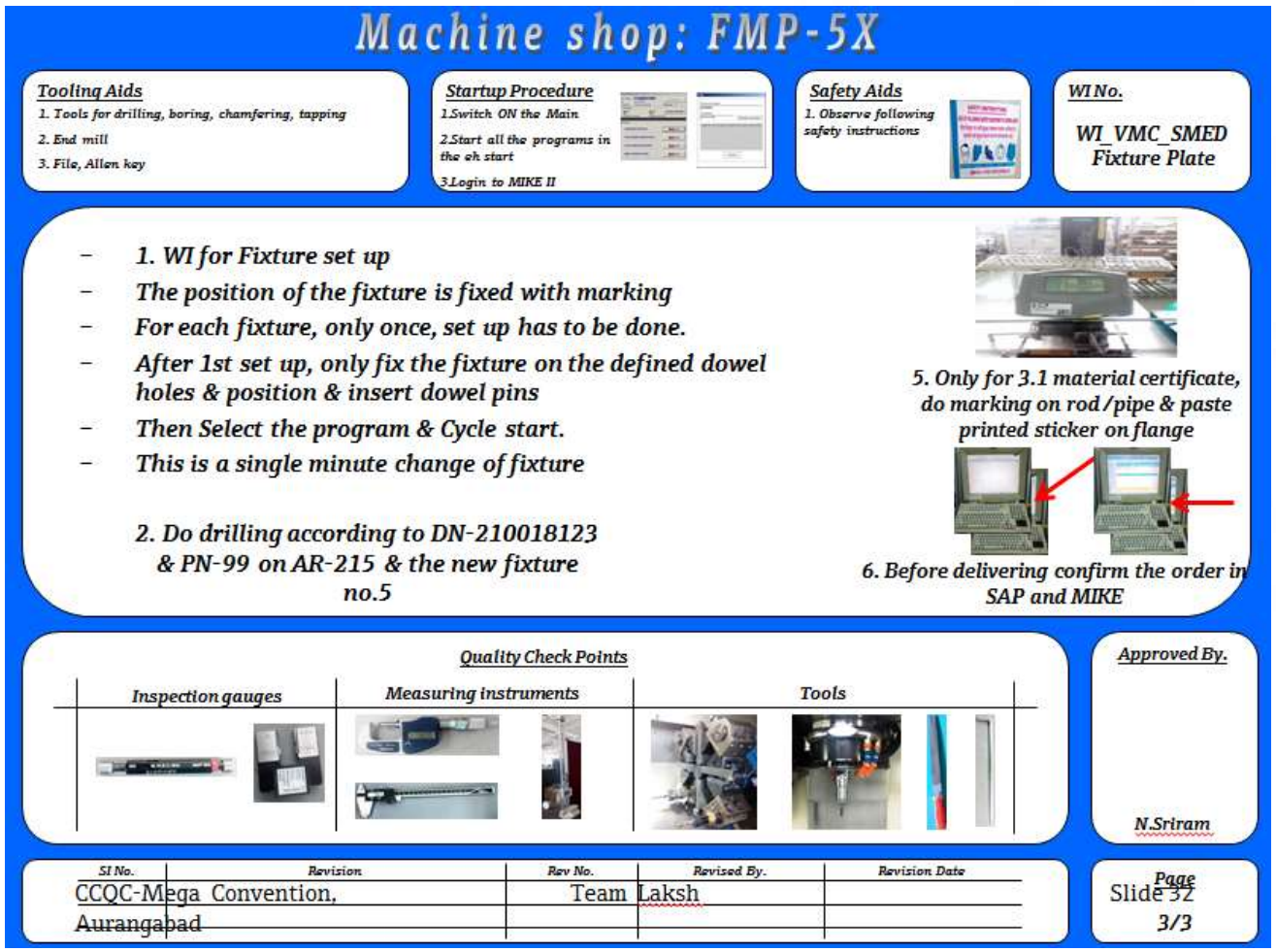


Following are some Tangible $\&$ Intangible benefits of this Kaizen

\section{Tangible Benefits:} improved.

$\checkmark$ Customer is getting devices in time so he is placing more \& more orders

$\checkmark$ Almost Zero rejection

$\checkmark$ Investment:-

Fixture Cost: Rs.50000/-

Avg. cost of rejections / Month = Rs. 15000/-

$\checkmark$ ROI:-

$40000 / 15000=3$ months

\section{Excellent $\div$}

\section{Intangible Benefits:}

$\checkmark$ No Operator Fatigue

$\checkmark$ Presentation skill improved.

$\checkmark$ Team work improved.

$\checkmark$ Motivation for more \& more Kaizens in the shop floor 